\title{
OPTIMIZATION PERFORMANCE OF BIOLOGICAL CATHODIC PROTECTION SYSTEM USING ORGANIC WASTE
}

\author{
E. Masri, *M. D. M. Samsudin \\ School of Chemical and Energy Engineering, Faculty of Engineering, Universiti Teknologi Malaysia, 81310 UTM Johor Bahru, Johor. \\ *Corresponding author: dinie@utm.my esuarny.es@gmail.com
}

This is an open access article distributed under the Creative Commons Attribution License, which permits unrestricted use, distribution, and reproduction in any medium, provided the original work is properly cited

\section{ARTICLE DETAILS}

\section{Article History:}

Received 10 May 2018

Accepted 6 Jun 2018

Available online 10 July 2018

\section{ABSTRACT}

In this study, the concept of Microbial Fuel Cells (MFCs) is applied in the biological cathodic protection (CP) system. MFCs are a promising technology for electricity production from a variety of materials. Impressed current cathodic protection (ICCP) was the tradition method used in corrosion control method. Biological CP uses the microbiological presence in wastewater to generate the electrons. The focus of this study is on the effect of organic waste towards the biological CP system. The selected organic wastes are orange peel and pineapple peel. The presence of starch and sugar in the organic waste are promote the microbial growth and increase the performance of biological CP system. The method used to prepare the substrate was based on the previous studies and the CP system was a single chamber system. Current and power density was calculated from the experimental data of the specific weight of substrates and the results was discussed in this study. The weight of substrate are manipulated for each experiment. The statistical analysis was done on the voltage potential output for the selected optimum substrate's weight and the result was varies for each of organic waste used. The highest voltage potential output by the CP system was $920 \mathrm{mV}$ ( $20 \mathrm{grams}$ of orange peel) and $1046 \mathrm{mV}$ (40 grams of pineapple peel).

\section{KEYWORDS}

CP system, Biological, microbiological

\section{INTRODUCTION}

Petrochemical industry uses pipe as the distribution and transmission medium for gas product and for the storage of the component. Carbon steel is commonly used as pipe material because of its superior strength and affordability compare to other engineering material. However, the contrast is that steel undergoes corrosion, which is the degradation of steel over time. The degradation of steel material is due to the electrochemical reaction of steel. Despite the fact that pipelines offer a safe, economical way to transport natural gas and dangerous liquids but the effect from pipeline leaks and ruptures from the corrosion factor can result in disastrous consequences [1].

The average annual corrosion-related cost is estimated at $\$ 7$ billion to monitor, replace, and maintain these assets [2]. In China, a study estimated that the cost of corrosion was approximately 310 billion USD, representing about $3.34 \%$ of the gross domestic product [3]. This proves that corrosion in pipelines is a major problem in the industry and this problem will be worsen along the time if no action is taken to minimize the problem.

Several methods have been considered to minimize the corrosion cost. One of them are cathodic protection system. Cathodic protection (CP) is a widely-used technique to control natural corrosion of metal surfaces including underground pipes and ships through an electrochemical process. CP has been applied widely in industries including in the pipeline networks, shipping and storage tanks to minimize the corrosion rate. The principle of cathodic protection of steel is to reduce the corrosion to a level at which the corrosion rate of the metal is significantly low. By making the metal surface acts as cathode of an electrochemical cell, it will minimise the corrosion rate.

Microbial Fuel Cells was introduced as another initiative that manipulates the capability of electrogenic microorganism in wastewater such as Shewanella oneidensisi and G.sulfurreducens, which produce electricity conductive addition under anaerobic conditions. The performance of MFCs system are affected by various factors either physical or chemical aspects [4]. The focus of this study is on the optimizing the CP system by using the organic waste as substrate for the microorganisms.

The growth of electrogenic bacteria can be promoted by adding substrates which act like food for microorganism in the system. This will enhance their function and finally able to control the corrosion in gas pipeline. Sodium acetate, glucose and glycerol are commonly used as substrate in MFC system. The composition of these organic chemicals consist of starch and sugar that promote the growth of microorganism in wastewater. Instead of using the organic chemical, this study introduces the organic waste as the food specifically fruit peel waste, for the microorganism.

At a global level, $70 \%$ of biodegradable wastes that contain major source of nutrient typically originating from plant [5]. Orange peel and pineapple stem and peel are selected as the substrate in this study. The composition of sugar and starch in these fruit peels are supported from the previous study. The factors which promote the growth of microorganism may affect current density requirement to the material, but the interaction between the organic wastes to the microorganism growth is less reported. Therefore, in this study, statistical analysis was used to optimize the amount of substrate used in obtaining maximum power density of a single chamber biological CP.

\section{EXPERIMENTAL}

\subsection{Experimental Set up and Procedure}

Single chamber biological $\mathrm{CP}$ was constructed by using a rectangular acrylic beaker in dimension of $30 \mathrm{~cm}$ length x $20 \mathrm{~cm}$ width $\times 15 \mathrm{~cm}$ height The copper wire with external resistance of $74 \Omega$ was connected to the digital multimeter. Both anode and cathode electrodes were connected to digital multimeter in order to determine the voltage and current. 


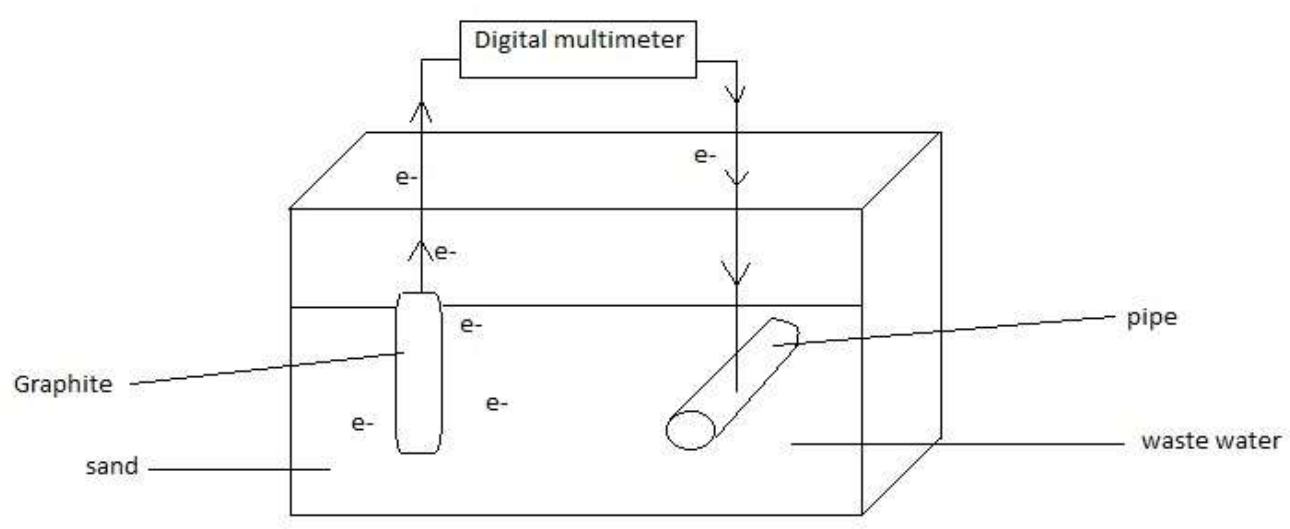

Figure 1: Schematic diagram of the experimental biological CP

Wastewater (2L) and sand (1L) was filled in the beaker and the ratio of wastewater and sand will be constant for all 14 runs. The graphite rod and carbon steel pipe are immersed in the sand. The substrate with vary amount of weight is fed into the system.

\subsection{Sample Preparation}

The anaerobic wastewater was chosen because of their microbial communities are at high concentration. An anaerobic wastewater was collected from gravity thickener pond at Indah Water Konsortium, Taman Bukit Senang, Senai. The anaerobic wastewater sample was kept below $4 \mathrm{oC}$ to deactivate the bacteria growth before feeding to the system.

\subsection{Material Selection}

\subsubsection{Anode Selection}

The graphite rod with dimension of $150 \mathrm{~mm}$ height $\times 20 \mathrm{~mm}$ outside diameter was used. Acid treatment for the graphite rod was run before the installation. The electrode was placed in the nitric acid solution for 24 hours. Then, graphite rod was removed and washed with deionized water for several times. This pre-treatment process will increase the active area of the anode surface and to minimize the impurities on the electrode surface [6].

\subsubsection{Cathode Selection}

Carbon steel pipe (schedule 40 pipe dimension) with size of $3 / 4$ inch, 26.67 $\mathrm{mm}$ outer diameter and $20.93 \mathrm{~mm}$ internal diameter was used. The pipe length of $1200 \mathrm{~mm}$ is used according to diameter of beaker. The total surface area of the pipe is calculated from the equation (1) below:

Total Surface Area, A $\left(m^{2}\right)=2 \pi r[r+l]$. Equation 1

where,

$\mathrm{r}$ : is the external radius of the pipe, $\mathrm{m}$

$l$ : is the total length of the pipe, $m$

In this experiment, the total surface of the carbon steel pipe is $0.01118 \mathrm{~m} 2$.

\subsection{Organic Waste Preparation}

\subsubsection{Orange peel}

Orange peel was dried and disintegrated using blender to a small size and homogenized in a single lot to avoid any variation in composition. The peel was stored at $4 \mathrm{oC}$ in a cold chamber until being used [7].

\subsubsection{Pineapple peel}

The pineapple peel are cut into small pieces about $10 \mathrm{~mm}$ in size. The peel was ground using distilled water by using blender. The weight ratio of pineapple peel to water are about $1: 1$. This reduce the piece size into paste and then the mixture need to be filtered out with a filter cloth. The filtrate fraction which contain starch and water-soluble compounds will be separated by centrifugal in order to collect the starch fraction from other extracted compound. The starch fraction requires addition of water to clean and remove water soluble materials. The mixture then will be separated and the pineapple peel starch cake is obtained. It will be dried in the oven at $60 \mathrm{oC}$ for 24 hours [8].
The weight of each substrates used are vary for each experiment. The matrix experiments (5 experiments with different combinations and another 2 runs for the optimum output current density of the CP system) is show in Table 1.

Table 1: Experimental Design Matrix for Orange and Pineapple Peel

\begin{tabular}{ccc}
\hline Run & Weight of Substrate $(\mathrm{g})$ & Volume of Wastewater (L) \\
& & \\
\hline 1 & 10 & 2 \\
2 & 20 & 2 \\
3 & 30 & 2 \\
4 & 40 & 2 \\
5 & 50 & 2 \\
6 & Optimum weight & 2 \\
7 & Optimum weight & \\
\hline
\end{tabular}

Note. Experiment was performed in batch mode.

Temperature and pressure was at ambient condition.

Wastewater was rest until reach the room temperature before feeding to the CP system.

\section{RESULTS AND DISCUSSION}

\subsection{Proximity Analysis}

The proximity analysis are carried out to identify the conditions and quality of the collected wastewater. The purpose of this analysis is to give limitation and reference values to the output value obtained in this or next study. The analysis on wastewater will be done before and at the end of experiment. The sample condition and results in average is shown in Table 2 that including the values of wastewater conductivity (Abron TDS Meter), salinity (Abron TDS Meter), pH (PHS-3D), temperature, COD (HANNA HI 83099) and total suspended solids (TSS).

Table 2: Proximity analysis results of collected wastewater

\begin{tabular}{cc|}
\hline Parameter & Reading Value \\
\hline Conductivity, $\mu \mathrm{MHOS}$ & 120 \\
Salinity, S \% & 0.10 \\
$\mathrm{pH}$ & 7.96 \\
Temperature, ${ }^{\circ} \mathrm{C}$ & 25 \\
Chemical Oxygen Demand (COD), mg/L & 388 \\
Total Suspended Solids (TSS), mg/L & 3793 \\
\hline
\end{tabular}

From the result tabulated in Table 2, the wastewater was in slightly basic condition and had the low conductivity, which was $122 \mu \mathrm{MHOS}$. The reading of COD obtained was quite low that showed low oxidization of organic, while the high reading in TSS indicated high turbidity in this water sample.

\subsection{Voltage Potential Reading}

The activity of bacteria in the waste water can be observed by the voltage potential reading in biological CP system. The trend of the graph must be the same as graph of bacterial growth. The voltage obtained according to the duration time from the designed matrix of substrate's weight were displayed in Figure 2(a) and 2(b).

\subsection{Experimental Design Matrix}




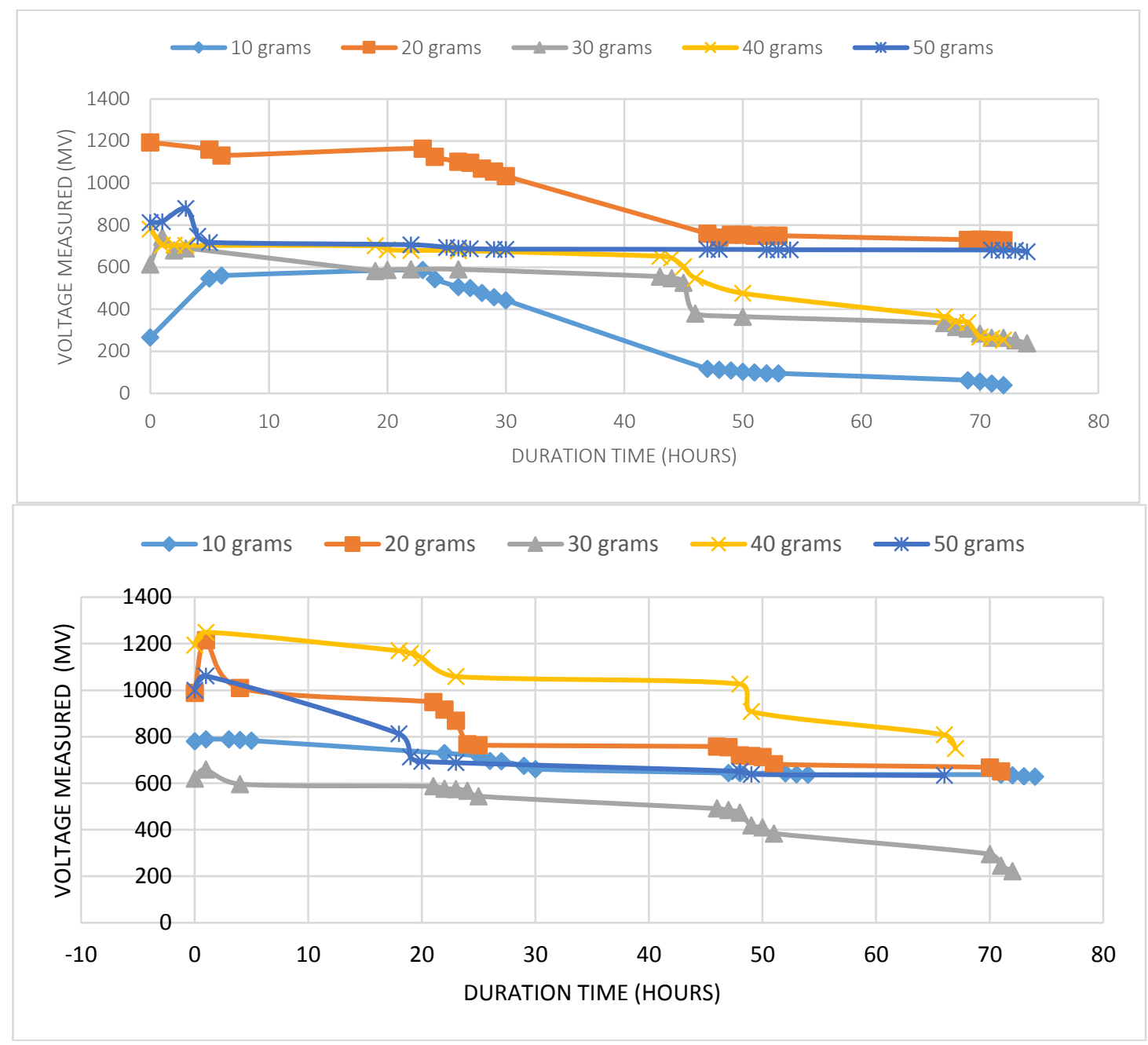

Figure 2: (a) Effect of Orange Peel on voltage reading, (b) Effect of Pineapple Peel on voltage reading

From Figure 2(a) and 2(b), it can be seen the data are flactuating at the beginning of experiment. At one moment the number were increasing and decreasing until the end of experiment. It could be observed that the voltage readings suddenly increased at an earlier experiment represents a period where the population of microorganism was continuously doubling. The process of doubling population of microorganism in this phase called exponential phase. This phase been continued until conditions become less favourable [9].

After certain duration time, the voltage readings were slightly constant due to the stationary phase of bacteria where the number of new cells were equal to the number of cells dying off. The role of subrate in this system is to provide enough food for the microorganism in result the microorganism can supply electron to the carbon steel more efficently before they reach the death phase. At the end the voltage readings started to drop due to the decline or death phase of microorganisms. When the nutrition of food supply finish, they will start to eat each other to survive until no living cells are present.

From Figure 2(a), it can be seen that by using 20 grams of orange peel the highest reading of voltage was obtained and Figure $2(\mathrm{~b})$ show 40 grams of pineapple peels gave the highest voltage value that the maximum power and current density output were achieved. Using this statement, 20 grams of orange peel and 40 grams of pineapple peel are selected as the optimum weight for the biological CP system in this study.

\subsection{Statistical Analysis Voltage Potential Reading}

The statistical analysis methodology was choosen as measurement of uncertainty for the experimental data. The statistical analysis was applied to the selected optimum weight of substrate. Another two runs of experiment was done to satisfy this analysis. The analysis includes standard deviation (SD), standard error (SE) and confidence interval (CI) at $95 \%$ by using equation (2), (3), and (4) respectively.

$$
s=\sqrt{\frac{1}{N-1} \sum_{i=1}^{n}\left(x_{i}-\bar{x}\right)^{2}}
$$

Equation 2

where;

s: standard deviation

$\mathrm{N}$ : number of sample

$\mathrm{xi}$ : individual values of $\mathrm{x}$ mean

$$
s_{M}=\frac{s}{\sqrt{N}}
$$

..Equation 3

$$
C I(\mu)=\bar{x} \pm \frac{t s}{\sqrt{N}}
$$

...Equation 4

where;

$\mathrm{t}$ : depend on degree of freedom, $\mathrm{v}(\mathrm{N}-1)$ and confidence level 95\% 

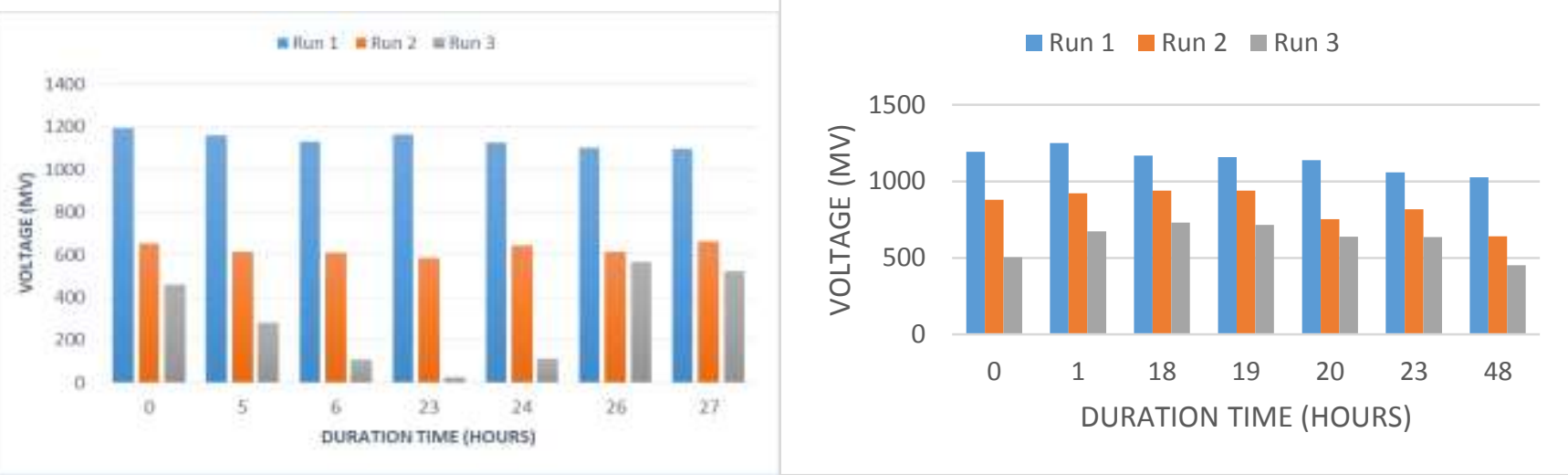

Figure 3: (a) Voltage reading for the 20 grams of orange peel, (b) Voltage reading for the 40 grams of pineapple peel

Table 3 (a): Statistical analysis of the optimum concentration orange peel substrate

\begin{tabular}{cccc}
\hline Run & $\begin{array}{c}\text { Standard } \\
\text { Deviation }\end{array}$ & $\begin{array}{c}\text { Standard } \\
\text { Error }\end{array}$ & Confidence Level \\
\hline 1 & 192.23 & 41.95 & $920.04 \pm 87.25$ \\
2 & 27.66 & 10.45 & $626.14 \pm 24.72$ \\
3 & 222.13 & 83.96 & $295.7143 \pm$ \\
& & & 198.5612 \\
\end{tabular}

Table 3(b): Statistical analysis of the optimum concentration pineapple peel substrate

\begin{tabular}{cccc}
\hline Run & $\begin{array}{c}\text { Standard } \\
\text { Deviation }\end{array}$ & $\begin{array}{c}\text { Standard } \\
\text { Error }\end{array}$ & Confidence Level \\
\hline 1 & 171.31 & 54.17 & $1046 \pm 120.70$ \\
2 & 112.52 & 42.53 & $841.57 \pm 100.58$ \\
3 & 105.40 & 39.84 & $621 \pm 94.21$ \\
& & & \\
\hline
\end{tabular}

The distribution of data about the mean can be seen through SD. The histogram Figure 3(a) and 3(b) shows that the data obtained have small value of SD because all the data are more closely packed to each other. The value of SD shows in Table 3(a) 192.23, 27.66 and 222.13 for the Run 1, 2 and 3 respectively reflects a small amount of variation in the data group obtained. The SE is an indication of the reliability of the mean of data, which small SE indicate that the experimental mean is a more accurate reflection of the actual situation mean. As observed the calculated SE for Run 2 (orange peel substrate) is 10.45 , being relatively small, gives a platform that mean for this part is relatively close to the true mean of overall data. The margin of error (at $95 \%$ confidence) for the mean is roughly is \pm 24.72 , which clarify the true mean is most likely between 601.42 and 650.86 .

This conclude, the small value of standard deviation and standard error indicated the lesser uncertainty and more the confidence in the experiment data. Thus higher the reliability of the experiment.

\subsection{Electrode Potential Reading}

The potential of an electrode in an electrolyte was determined using the reference electro potential reading. Figure 4(a) and 4(b) shows the electro potential reading at an interval time for each experiment. The values of electro potential were steadily increase until the end of experiment. If the electrode potential of the structure was more negative than $-850 \mathrm{mV}$ measured against a saturated copper/copper sulphate electrode, which is indicate the best performance in typical application of $\mathrm{CP}$ in soils are achieved [10]. However, the values in this study were not achieved -850 $\mathrm{mV}$. The maximum values achieved are in the ranges of $-625 \mathrm{mV}$ to -605 $\mathrm{mV}$.

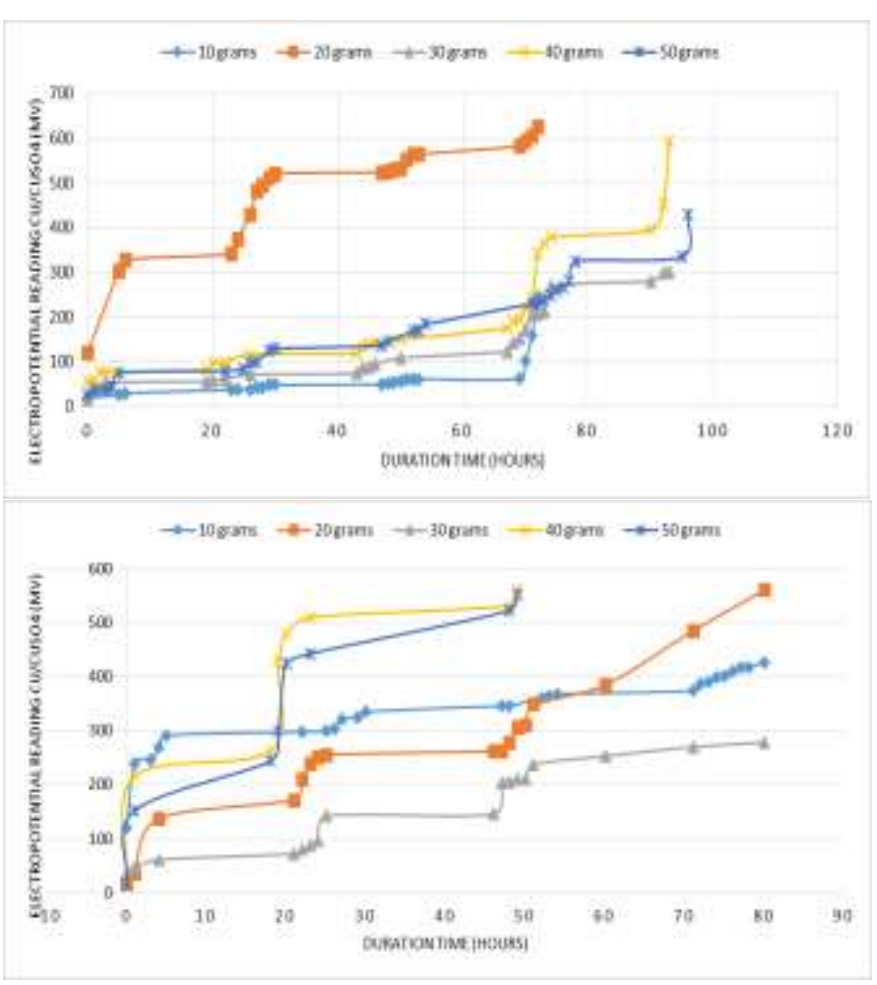

Figure 4: (a) Effect of orange peel on the electrode potential reading, (b) Effect of pineapple peel on the electrode potential reading

\subsection{Result of the Organic Waste on Performance of Biological Cathodic Protection System}

The effect of using organic waste in the biological cathodic protection system were anaylse based on current density and power density performance of the system. Two type of organic waste used which is each of them contain different major components (starch and sugar) favourable as food for the microorganism. The current generation of the system varies according to the performance of electrogens in the wastewater. Low values of current generation might related to the poor electrons and protons supplied to the cathode (carbon steel). Thus, organic waste was feed to the system to simulated the electrogens and give the power to the CP system. From Table 4 ,weight of $20 \mathrm{~g}$ orange peel and $40 \mathrm{~g}$ pineapple peel gave a high open circuit average voltage of $920.05 \mathrm{mV}$ and $1046 \mathrm{mV}$ respectively. The average current density and power density for both variable also has the highest value in the group. Based on the result, the CP system more favour the starch composition in pineapple peel than sugar in orange peel. As can be seen, the trend of voltage and current generation in CP system that supported by organic waste shows slightly different compare to he system that feed with organic chemical as the subsrate. Thus clarify, organic waste can be new initiative to optimize the biological cathodic protection system beside organic chemical source. This supported with evidence of advantage of using organic waste, one of them are economical and enviromental friendly source. 
Table 4: Effect of the organic waste on performance of biological cathodic protection system

\begin{tabular}{cccc|ccc}
\hline \multicolumn{2}{c|}{ Orange Peel } & \multicolumn{3}{c}{ Pineapple Peel } \\
\hline Exp & $\begin{array}{c}\text { Average Voltage } \\
(\mathbf{m V})\end{array}$ & $\begin{array}{c}\text { Average Current } \\
\text { Density } \\
\left(\mathbf{m A} / \mathbf{m}^{2}\right)\end{array}$ & $\begin{array}{c}\text { Average Power } \\
\text { Density } \\
\left(\mathbf{m w} / \mathbf{m}^{2}\right)\end{array}$ & $\begin{array}{c}\text { Average Voltage } \\
(\mathbf{m V})\end{array}$ & $\begin{array}{c}\text { Average Current } \\
\text { Density } \\
\left(\mathbf{m A} / \mathbf{m}^{2}\right)\end{array}$ & $\begin{array}{c}\text { Average Power } \\
\text { Density }\left(\mathbf{m w} / \mathbf{m}^{2}\right)\end{array}$ \\
\hline $10 \mathrm{~g}$ & 277.67 & 0.0186 & 8.9003 & 673.23 & 0.1518 & 102.1180 \\
$\mathbf{2 0} \mathrm{g}$ & $\mathbf{9 2 0 . 0 5}$ & $\mathbf{0 . 1 6 7 7}$ & $\mathbf{1 5 3 . 5 5 8 4}$ & 821.06 & 0.1178 & 95.2089 \\
$30 \mathrm{~g}$ & 433.25 & 0.0437 & 19.0221 & 479.24 & 0.0470 & 23.6181 \\
$\mathbf{4 0} \mathrm{g}$ & 564.71 & 0.0454 & 20.7292 & $\mathbf{1 0 4 6 . 0 0}$ & $\mathbf{0 . 2 1 9 0}$ & $\mathbf{2 3 9 . 0 3 4 0}$ \\
$50 \mathrm{~g}$ & 697.65 & 0.1651 & 113.2482 & 765.44 & 0.1101 & 84.3117 \\
\hline
\end{tabular}

\section{CONCLUSION}

The performance for single chamber of biological CP system were affected by the substrate, in this study organic waste is used. The weight of waste should be determined if the system used does not fulfill the scope of this study because different condition of system might gave different result. The statistical analysis method could be applied as the measurement of uncertainty experimental data in order to obtain the best weight of substrate used. In this study, the optimum weight of substrate which was $20 \mathrm{~g}$ of orange peel and $40 \mathrm{~g}$ of pineapple, gave the maximum performance of biological CP. Based on the results obtained, the substrate affected the microbial metabolism and proton conductivity in biological CP system.

Microbial metabolism was important in order to make sure sufficient electrons are transfer to the carbon steel (cathode) in longer period of time. The values of output obtained were used in statistical analysis method to determine the optimize parameter. The right substrate's weight was enhanced the performance of biological CP system. From this study, it could be concluded that some improvement need to be implied in the system to obtain higher performance of biological CP.

\section{ACKNOWLEDGEMENT}

We are grateful for the UTM scholarship to corresponding author.

\section{REFERENCES}

[1] Khattak, M.A., Zareen, N., Mukhtar, A., Kazi, S., Jalil, A., Ahmed, Z. 2016. Root cause analysis (RCA) of fractured ASTM A53 carbon steel pipe at oil \& gas company. Case Stud Eng Fail Anal [Internet]. 7, 1-8. Available from: http://dx.doi.org/10.1016/j.csefa.2016.04.002

[2] Gerhardus, H., Koch, M.P.H., Brongers, NGTYPVJHP. 2012. Corrosion costs and preventive strategies in the United States. Summ Shute Inst., 112. Available from: papers2://publication/uuid/4D469A9D-07D6-4543B217-3A15873793CF
[3] Hou, B., Li, X., Ma, X., Du, C., Zhang, D., Zheng, M. 2017. The cost of corrosion in China. npj Mater Degrad, 1 (1), 4. Available from: http://www.nature.com/articles/s41529-017-0005-2

[4] Wilkinson, S.C., Anderson, J.M., Scardelis, S.P., Tisiafouli, M., Taylor, A., Wolters, V. 2002. PLFA profiles of microbial communities in decomposing conifer litters subject to moisture stress. Soil Biol Biochem., 34 (2), 189200 .

[5] Amritha, P.K., Anilkumar, P.P. 2016. Development of Landscaped Landfills Using Organic Waste for Sustainable Urban Waste Management. Procedia Environ Sci., 35, 368-376. Available from: http://linkinghub.elsevier.com/retrieve/pii/S1878029616301050

[6] Santoro, C., Arbizzani, C., Erable, B., Ieropoulos, I. 2017. Microbial fuel cells: From fundamentals to applications. A review. J Power Sources, 356, 225-244. Available from http://dx.doi.org/10.1016/j.jpowsour.2017.03.109

[7] Torrado, A.M., Cortés, S., Salgado, J.M., Max, B., Rodríguez, N., Bibbins, B.P. 2011. Citric acid production from orange peel wastes by solid-state fermentation. Brazilian J Microbiol, 42 (1), 394-409.

[8] Nakthong, N., Wongsagonsup, R., Amornsakchai, T. 2017. Characteristics and potential utilizations of starch from pineapple stem waste. Ind Crop Prod, 105, 74-82. Available from: http://dx.doi.org/10.1016/i.indcrop.2017.04.048

[9] Rolfe, M.D., Rice, C.J., Lucchini, S., Pin, C., Thompson, A., Cameron, A.D.S. 2012. Lag phase is a distinct growth phase that prepares bacteria for exponential growth and involves transient metal accumulation. J. Bacteriol., 194 (3), 686-701.

[10] Kuang, D., Cheng, Y.F. 2015. Study of cathodic protection shielding under coating disbondment on pipelines. Corros Sci., 99, 249-57. Available from: http://dx.doi.org/10.1016/j.corsci.2015.07.012 